Research Article

\title{
Crystallization Behavior of Ammonium Chloride in High-Pressure Heat Exchanger of Hydrotreating Unit
}

\author{
Jianwen Zhang $\mathbb{D}^{1,2}$ Fan Zhang $\mathbb{D}^{1},{ }^{1}$ Yan Li, ${ }^{1}$ Yahui Zhao, ${ }^{1}$ and Gang Sheng ${ }^{3}$ \\ ${ }^{1}$ Lab of Fluid Flow and Heat Transfer and IGCIT, Beijing University of Chemical Technology, Beijing 100029, China \\ ${ }^{2}$ Department of Mechanical and Electrical Engineering, Beijing University of Chemical Technology, Beijing 100029, China \\ ${ }^{3}$ Lanzhou Petrochemical Research Institute, Lanzhou, Gansu 730000, China
}

Correspondence should be addressed to Jianwen Zhang; zhangjw@mail.buct.edu.cn

Received 7 September 2021; Accepted 23 November 2021; Published 28 December 2021

Academic Editor: Seralathan Sivamani

Copyright ( $\odot 2021$ Jianwen Zhang et al. This is an open access article distributed under the Creative Commons Attribution License, which permits unrestricted use, distribution, and reproduction in any medium, provided the original work is properly cited.

In view of the corrosion failure of a high-pressure heat exchanger in a diesel hydrogenation unit, the formation mechanism of ammonium chloride in a multiphase flow system is investigated in this article. Numerical simulation is carried out by user defined function (UDF) on the process of adding source of mass transfer in computational fluid dynamics (CFD) solvers. The distribution characteristics of ammonium chloride are illustrated by the parameters including crystallization temperature of ammonium chloride, volume fraction of ammonium chloride, and mass transfer rates of $\mathrm{NH}_{3}$ and $\mathrm{HCl}$, and the causes of corrosion cracking in the $\mathrm{U}$-shaped bend of the heat exchanger are discussed. The results show that there is a great risk of ammonium chloride deposition in the heat exchanger from $4.5 \mathrm{~m}$ away from the outlet of the second pass. The crystallization area in the tube gradually expands from the wall to the center along the flow direction, and the crystallization rate is higher near the tube wall. The field sampling test results show that the corrosion cracking is hydrogen-induced cracking, which is due to the existence of large amount of hydrogen, high impacting force, excessive flow rate, and the risk of ammonium chloride particle erosion at the U-bend. In order to alleviate the corrosion of ammonium chloride deposition, some improvement measures are put forward, such as raising the inlet temperature of the tube side to $215^{\circ} \mathrm{C}$ and increasing the water injection by $30 \%$, which play an important role in decreasing the formation of ammonium chloride in the heat exchange system.

\section{Introduction}

The petrochemical industry is one of the pillar industries for national economy and security, and the hydrogenation device is the core equipment of oil refining industry. With the increasingly diversified, heavy, and inferior sources of international crude oil, the content of sulfur, nitrogen, and chlorine in the raw oil is increasing. In the procedure of crude oil processing, due to the fluid-containing corrosive substance and the variations in the operating conditions, the heat exchangers are prone to form ammonium salt, causing tubes corrosion thinning and perforation failure. Moreover, there are also tubes explosion accidents, which seriously affect the safety of production, making it a common problem in the chemical industry [1-3].
The problem of ammonium salt crystallization generally exists in the process devices of the hydrogenation unit, especially in the heat exchange system. It is reported frequently that there appear various erosion-corrosion of ammonium chloride in the high-pressure heat exchanger in the diesel hydrogenation unit. However, the understanding of the ammonium chloride crystallization process is really poor, which is mainly reflected in the following aspects. Ammonium chloride crystallization and salt formation are two different concepts. Crystallization is an extremely tiny process: the precipitation process of $\mathrm{NH}_{4} \mathrm{Cl}$ particles in crystal form generated by the gaseous reaction of $\mathrm{HCl}$ and $\mathrm{NH}_{3}$ under operation conditions. Salt formation is the accumulation of a large amount of $\mathrm{NH}_{4} \mathrm{Cl}$ crystals into a visible white or yellow solid [4-6]. At present, no research has been performed on the internal mechanism of ammonium 
chloride crystallization, nor on where to crystallize first inside. Most of the research studies on the corrosion failure analysis of hydrogenation equipment is to carry out corrosion classification on the surface, which is far clear away from the mechanism of the crystallization behavior, and there is no real in-depth study on the ammonium chloride crystallization behavior. To prevent the deposition of ammonium chloride, water washing systems are commonly used in hydrogenation units. However, the water injection method and the amount of water injection are disconnected with ammonium chloride corrosion, which does not essentially indicate that water injection can alleviate the corrosion process $[7,8]$.

The erosion-corrosion phenomenon in the multiphase flow is mainly divided into two types: gas-solid two-phase erosion-corrosion and liquid-solid two-phase erosion-corrosion [9-11]. As for the crystallization behavior of ammonium chloride, the gas phase is concentrated in the tubes located at the upper part of the heat exchanger. And the formation of ammonium chloride is a rapid gas-phase reaction, which is first formed in the upper region within the tubes. Therefore, the gas phase and ammonium chloride particles filled in the upper layer of the tubes are typical gassolid two-phase erosion-corrosion. When ammonium chloride continuously spreads in the upper tubes and falls to the bottom of the tubes, it forms a typical liquid-solid erosion-corrosion with the liquid phase in the lower layer. The crystallization process of ammonium chloride includes both gas-solid erosion-corrosion and liquid-solid erosioncorrosion. In addition, since the crystallization reaction of ammonium chloride is affected by complicated coupling of temperature field, flow field, and composition field, the transformation mechanism is more complex and difficult [12]. The researchers mainly qualitatively describe the failure mechanism through corrosion characterization parameters combined with experimental simulation. There are few quantitative studies on the crystallization process of ammonium chloride in the heat exchange system, and there are few studies on the behavior of ammonium chloride in the tubes [13-17].

In this article, the corrosion mechanism and mathematical prediction model of the corrosion site of the tubes are constructed based on the actual process to investigate the problem of crystallization and corrosion of high-pressure heat exchangers. As for the formation process of ammonium chloride, the transformation mechanism of ammonium chloride in a multiphase flow system is proposed. Based on the thermodynamic phase diagram of ammonium chloride crystallization, the user defined function (UDF) is compiled into numerical simulation software Fluent. The formation conditions and distribution characteristics of ammonium chloride are studied, and the corrosion-erosion mechanism of the heat exchanger is analyzed by using the crystallization temperature, volume fraction, and formation rate of ammonium chloride as characteristic parameters. The flow field, temperature field, and composition distribution in the high-pressure heat exchanger are explored. Combined with the on-site corrosion situation and sampling test results, the causes of U-bend corrosion cracking are analyzed. Further on, specific improvement measures are put forward to decrease the crystallization of ammonium chloride and reduce the occurrence of ammonium chloride corrosion failures.

\section{Failure Analysis}

2.1. The Process Flow. The diesel hydrogenation process involves seven high-pressure heat exchangers and air coolers, as shown in Figure 1. The raw oil of the device is catalytic diesel oil and straight-run diesel oil, with the processing capacity of $150 \mathrm{t} / \mathrm{h}$. The content of sulfur, nitrogen, and chlorine in the raw oil is $301.01 \mathrm{ppm}$, $640.95 \mathrm{ppm}$, and $1.46 \mathrm{ppm}$, respectively. The reactants flow into R1101 for diesel hydrogenation reaction, and the reaction outflow flows into three heat exchangers E1103 A/B/C through E1101 and E1102 heat exchangers and then flows out of the air cooler A1101. The flow in the tubes of the heat exchanger enters from the top and flows out from the bottom. The shell side flows in the opposite direction. To prevent the formation and deposition of ammonium chloride, two intermittent water injection points are set: one is injected before heat exchanger E1103 $\mathrm{A}$ and the other is injected before air cooler A1101. The operating temperature and pressure of tube and shell sides of heat exchanger E1103 B are shown in Table 1.

During the operation, the high-pressure heat exchanger E1103 B suddenly suffered internal leakage. E1103 B heat exchanger is a typical horizontal two-way U-shaped tubeand-shell heat exchanger, its model is DFU1300-7.9/ 9.42-598-6.4/19-2/2I, the material of the tube is S32205, and the shell is $15 \mathrm{CrMoR}$ with surfacing welding.

2.2. Field Failure Analysis. After the internal leakage of highpressure heat exchanger E1103 B, the tubes were inspected and it was found that there were circumferential fractures at the U-shaped bend, white scaling at the outlet of the tubes, and different small cracks on the tube sheet. The U-bend fracture, salt crystallization in the tubes, and tube sheet crack are shown in Figures 2-4. The heat exchanger tubes were checked with an endoscope, and it was found that significant deposits of ammonium chloride appeared in some tubes.

The crack analysis of the fracture site of the heat exchange tube was carried out. The metallographic analysis found that the metallographic structure was austenite, martensite, and ferrite, and the outer wall structure was coarser than the inner wall. There were microcracks that penetrate and propagate outward along the thickness of the tube wall. There were smooth and straight microcracks on the tube surface, and there were partial bifurcations, which were typical hydrogen-induced cracking characteristics, accompanied by stress corrosion cracking characteristics [18]. The analysis by scanning electroscope and energy spectrum found that there existed many corrosion products on the surface of the break, of which $\mathrm{Cl}, \mathrm{O}$, and $\mathrm{S}$ contents were higher. The fracture in the interrupt area was quasi-solution fracture characteristic with claw torn edges. The spectrum analysis showed that the content of $\mathrm{Ni}$ and $\mathrm{Ti}$ in cracked heat 


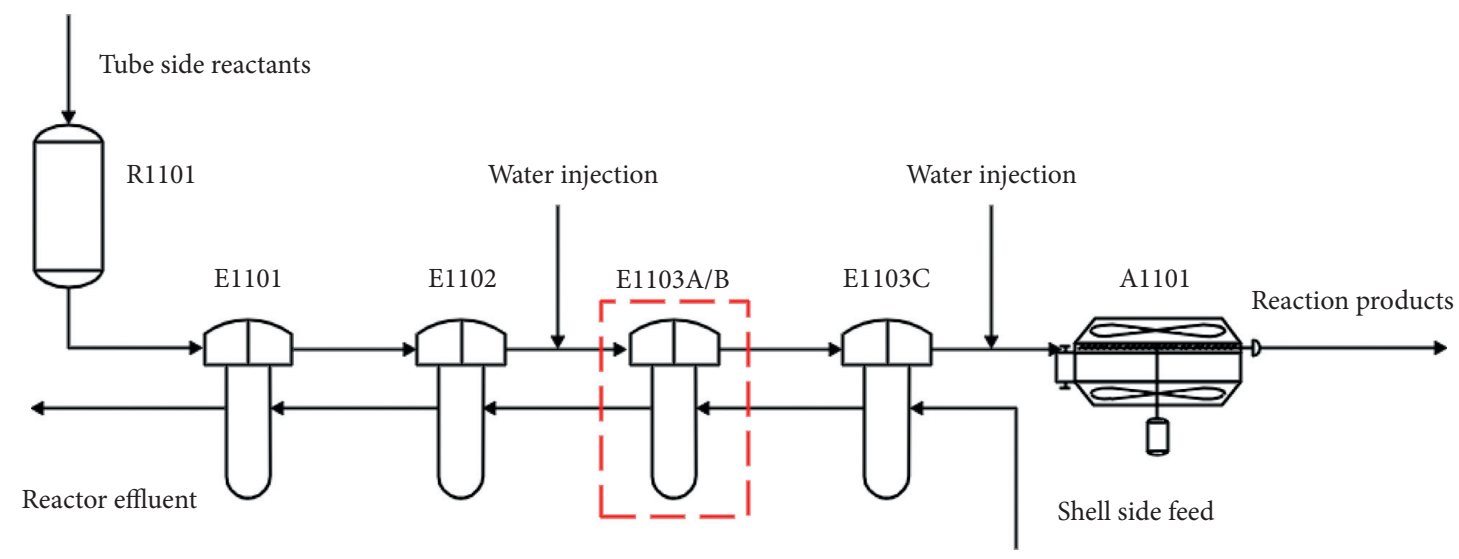

FIgure 1: Process flow chart of the diesel hydrogenation unit.

TABLE 1: Operating conditions of heat exchanger E1103 B.

\begin{tabular}{lccc}
\hline & Inlet temperature $/{ }^{\circ} \mathrm{C}$ & Outlet temperature $/{ }^{\circ} \mathrm{C}$ & Outlet pressure $/ \mathrm{MPa}$ \\
\hline Tube side & 176 & 147.3 & 7.1 \\
Shell side & 122.5 & 153 & 8.9 \\
\hline
\end{tabular}

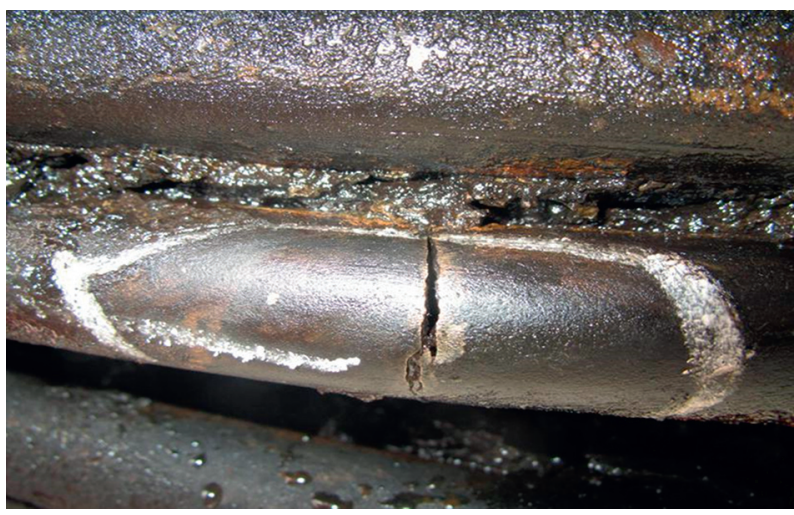

FIgURE 2: U-bend fracture.

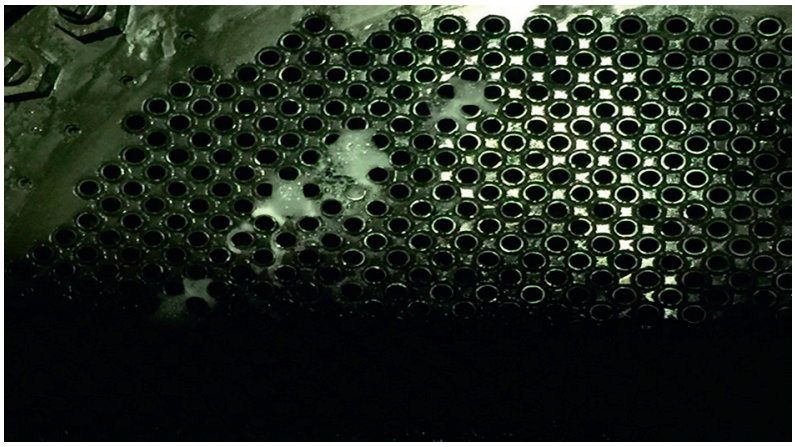

Figure 3: Salt crystallization in the tubes.

exchange tubes was lower than the technical requirements of GB/t13296-2007. In conclusion, the heat exchanger produced a large amount of hydrogen-induced martensite in the acidic environment, and the microstructure deterioration, and hydrogen-induced cracking $[19,20]$. Part of the white scale was analyzed, showing that was a large amount of ammonium salt scale compounds. It can be concluded that the main composition of the white scale deposited in the tubes of the heat exchanger was ammonium chloride. 


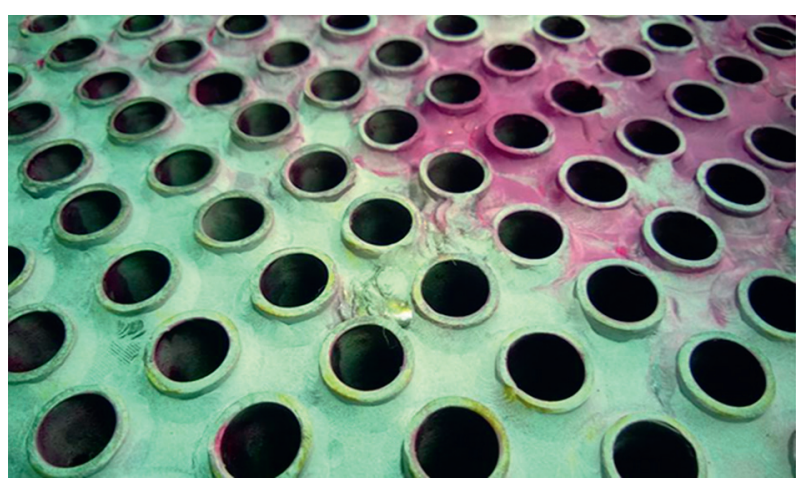

Figure 4: Crack of the tube sheet.

\subsection{Crystallization Analysis of Ammonium Chloride}

\subsubsection{Ammonium Chloride Salt Transformation Mechanism.} The heat transfer process and the composition transfer and transformation mechanism in the multiphase flow system are extremely complex. With the heat transfer process, the temperature distribution in the heat transfer system changes, and as the change of the temperature field, the transformation of the composition in the gas phase of the multiphase flow system will be triggered. The raw oil contains a large amount of nitrogen, chlorine, and other elements, which will be converted into the corrosive media $\mathrm{HCl}$ and $\mathrm{NH}_{3}$ during the hydrogenation reaction. In the continuous heat exchange process, due to the large specific heat capacity of the gas, the upper temperature of the tubes first decreases to the crystallization temperature of $\mathrm{NH}_{4} \mathrm{Cl}$, and then, rapid gas reaction will occur between $\mathrm{HCl}$ and $\mathrm{NH}_{3}$ under a certain pressure to generate $\mathrm{NH}_{4} \mathrm{Cl}$ and precipitate out. The equation is as follows:

$$
\mathrm{NH}_{3}(\mathrm{~g})+\mathrm{HCl}(\mathrm{g}) \longrightarrow \mathrm{NH}_{4} \mathrm{Cl}(\mathrm{s})
$$

Under the action of gravity, buoyancy, and drag force, some of the generated $\mathrm{NH}_{4} \mathrm{Cl}$ particles will fall down and deposit at the bottom of the tube, whereas others will attach to the top of the tube and continue to spread and block the tube. The formation process of ammonium salt in multiphase flow system is shown in Figure 5. Because the chlorinated ammonium salts are hydraulics and easily to absorb water, API 571 states that small amounts of water can cause severe corrosion. Ammonium chloride is highly watersoluble and corrosive, forming acid solution when mixing with water and forming acid corrosion environment [18]. The deposited ammonium chloride is attached to the inner wall of the tube, which will gradually corrode and destroy the metal oxide film, resulting in corrosion thinning [21, 22]. The deposited ammonium chloride is usually dissolved into the solution by the injection of water. There are two ways to fill the water continuously and intermittently, but the amount of water injection still needs to be carefully discussed.

2.3.2. Crystallization Temperature Analysis. In order to effectively alleviate the formation of ammonium chloride, the distribution characteristics of crystal temperature in tubes must be obtained. According to the thermodynamic gas phase diagram of ammonium chloride crystallization provided in API RP 932-B [23], the crystallization equilibrium equation of $\mathrm{NH}_{4} \mathrm{Cl}$ is deduced, as shown in equation (2):

$$
T=0.745569 *[\operatorname{Lg}(\mathrm{Kp})]^{2}+24.047921 * \operatorname{Lg}(\mathrm{Kp})+216.3938 .
$$

Figure 6 shows the crystallization equilibrium curve of $\mathrm{NH}_{4} \mathrm{Cl}$. As shown in the figure, the temperature of the medium in tubes decreases gradually with the heat exchange process of the heat exchange system. When the local temperature is below the crystallization temperature of $\mathrm{NH}_{4} \mathrm{Cl}$, the multiphase system will cross the equilibrium crystalline curve into the crystalline region, resulting in $\mathrm{NH}_{4} \mathrm{Cl}$ particles. In this article, the UDF is proposed based on the equilibrium curve equation and loaded into numerical simulation software.

According to the composition distribution of heat exchanger E1103 B under actual operating conditions, the thermal decomposition constant of ammonium chloride at the inlet of tubes is calculated and the crystallization equilibrium temperature of ammonium chloride is $196.07^{\circ} \mathrm{C}$. However, the inlet temperature of $176^{\circ} \mathrm{C}$ is lower than the crystallization temperature. Under this condition, ammonium chloride is produced when the fluid flows into tubes of the E1103 B heat exchanger.

\section{Numerical Simulation}

3.1. Governing Equations. The flow process of the fluid medium in tubes of the Heat exchanger obeys the law of continuity equation, momentum equation, the equation of conservation of energy, and the equation of conservation of compositions [24]:

(1) Continuity equation

$$
\frac{\partial \rho}{\partial t}+\frac{\partial(\rho u)}{\partial x}+\frac{\partial(\rho v)}{\partial y}+\frac{\partial(\rho \omega)}{\partial z}=0
$$

where $\rho, t$ is the density and flow time of the fluid, and $u, v$, and $\omega$ are vector velocity values in three directions $x, y$, and $z$, respectively. 


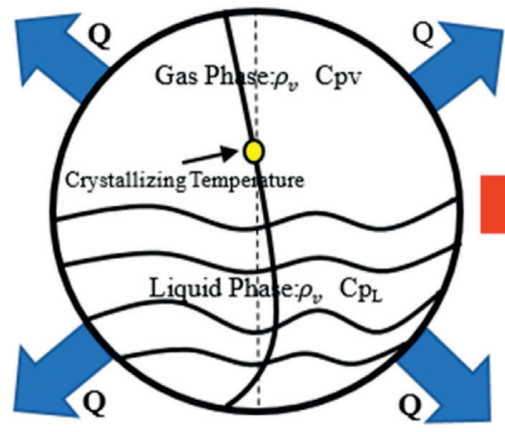

Multiphase flow reaction system

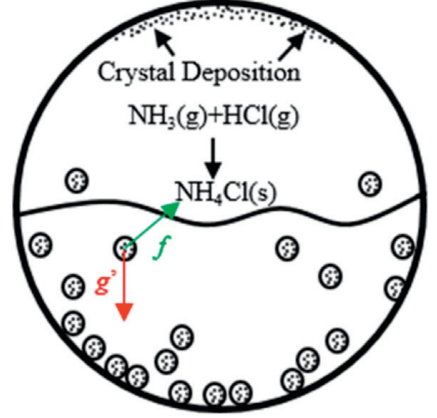

Ammonium salt formation

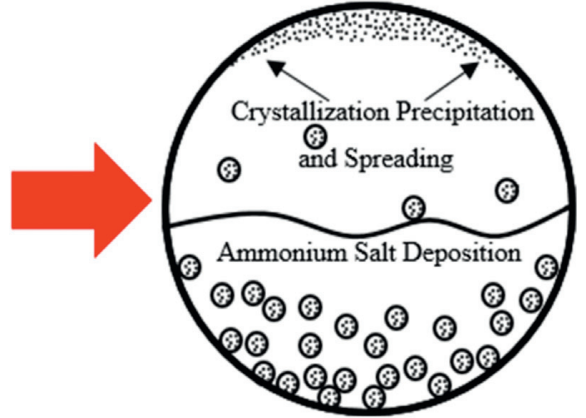

Ammonium salt deposition

Figure 5: Ammonium salt formation process in the multiphase flow system.

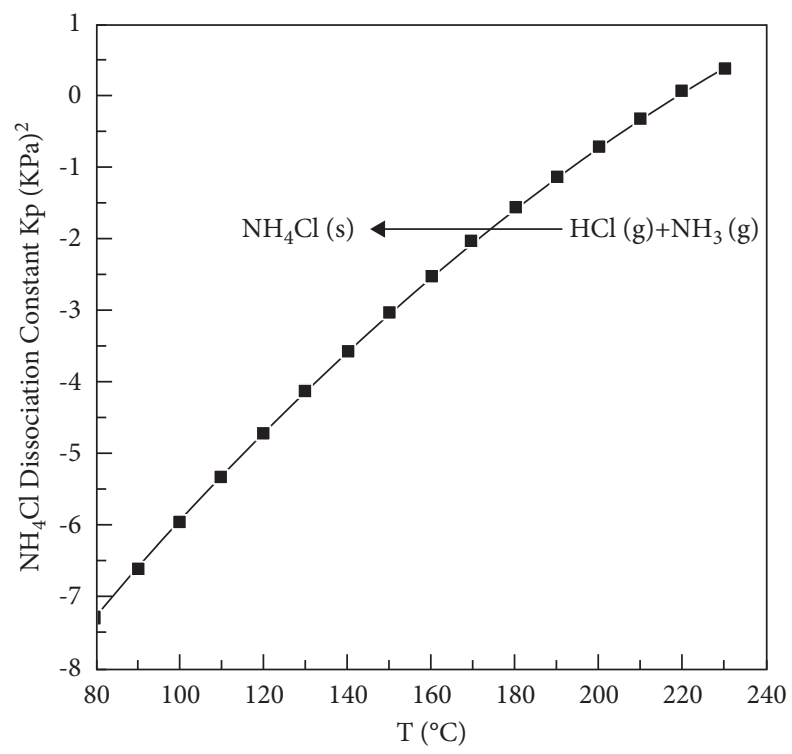

Figure 6: Crystallization equilibrium curve of ammonium chloride.

(2) Momentum equation

$\frac{\partial(\rho u)}{\partial t}+\operatorname{div}(\rho u u)=-\frac{\partial p}{\partial x}+\frac{\partial \tau_{x x}}{\partial x}+\frac{\partial \tau_{y x}}{\partial y}+\frac{\partial \tau_{z x}}{\partial z}+F_{x}$,

$\frac{\partial(\rho \nu)}{\partial t}+\operatorname{div}(\rho u \nu)=-\frac{\partial p}{\partial y}+\frac{\partial \tau_{x x}}{\partial x}+\frac{\partial \tau_{y x}}{\partial y}+\frac{\partial \tau_{z x}}{\partial z}+F_{y}$

$\frac{\partial(\rho \omega)}{\partial t}+\operatorname{div}(\rho u \omega)=-\frac{\partial p}{\partial z}+\frac{\partial \tau_{x x}}{\partial x}+\frac{\partial \tau_{y x}}{\partial y}+\frac{\partial \tau_{z x}}{\partial z}+F_{z}$,

where $\tau_{x x}, \tau_{y x}$, and $\tau_{z x}$ are the values of the viscous stress components in different directions, $P$ is the pressure in the multiphase flow medium, and $F_{x}, F_{y}$, and $F_{z}$ are the forces on the micro-elements of the medium, respectively.

(3) Energy conservation equation

$$
\frac{\partial}{\partial t} \rho_{m} h_{m}+\nabla \cdot\left(\rho_{m} h_{m} \overrightarrow{V_{m}}\right)+\nabla \cdot\left(P \overrightarrow{V_{m}}\right)=\nabla \cdot\left(k_{m} \nabla T\right)
$$

where $\rho_{m}$ is the density of the mixture, $h_{m}$ is the heat of the mixture, $k_{m}$ is the thermal conductivity of the mixture, $V_{m}$ is the velocity of the mixture, and $P$ is the pressure of the fluid [25].

(4) Composition conservation equation

$$
\frac{\partial}{\partial t}\left(\rho m_{1}\right)+\operatorname{div}\left(\rho u m_{1}+J_{1}\right)=R_{1}
$$

where $m_{1}$ is the composition of chemical component $1, R_{1}$ is the generation rate of chemical composition 1 at unit volume, and $J_{1}$ is the diffusion flow density. The diffusion flow density $J_{1}$ is expressed by Fick's diffusion law:

$$
J_{1}=-\Gamma_{1} \operatorname{grad} m_{1},
$$


where $\Gamma$ is the diffusion coefficient. The two formulas are combined as follows:

$$
\frac{\partial}{\partial t}\left(\rho m_{1}\right)+\operatorname{div}\left(\rho u m_{1}\right)=\operatorname{div}\left(\Gamma \operatorname{grad} m_{1}\right)+R_{1} .
$$

3.2. Geometric Models and Meshing. A three-dimensional geometric model is constructed according to the actual structure of heat exchanger E1103 B. In the light of the symmetry of the structure, half of the heat exchanger is selected as the calculation domain. The mesh is based on a hexagonal fit mesh, combining a triangular mesh with a mixed mesh model of a four-sided mesh. The grid scale reaches 14.91 million after merging the grids of each part with HYPERMESH. The accuracy of this grid is tested, and the obtained tube and shell side outlet temperatures are compared with the actual temperatures. The error is $1.03 \%$ shown in Table 2, which meets the requirements of calculation accuracy. The geometric model and mesh division of heat exchanger E1103 B are shown in Figures 7 and 8.

3.3. The Boundary Conditions. Since the internal fluid medium of heat exchanger E1103 B tubes contains multiphase, gas phase, oil phase, water phase, and ammonium chloride phase, interspersed between composition, and has a composition transfer and transformation mechanism, and the Mixture model is used for numerical simulation [26]. Wherein the gas phase is set to the main phase, the others are the secondary phase in turn. The turbulence model adopts shear-stress transport (SST) k-Omega model [27]. Considering interphase mass transfer, the UDF of the reaction of $\mathrm{HCl}$ and $\mathrm{NH}_{3}$ in the gas phase to $\mathrm{NH}_{4} \mathrm{Cl}$ in the solid phase is loaded. No slip boundary condition is adopted for the wall surface, pressure and velocity coupling is phase-coupled simply, and a first-order upwind solver is used for momentum, volume, turbulent kinetic energy, and turbulent dissipation rate [28]. Mass flow inlet and pressure outflow are imposed on the inlet and outlet boundary conditions of the heat exchanger, respectively. And the physical parameters of the medium are shown in Table 3 and 4.

\section{Results and Discussions}

In order to explore the crystallization behavior of the ammonium chloride in the tubes of the heat exchanger and the cause of U-bend cracking, the mechanism of ammonium chloride crystallization will be discussed, and the high-risk corrosionerosion location of the heat exchanger will be analyzed.

The overall temperature distribution along the tube of the heat exchanger is shown in Figure 9. The distributions of different phases in tubes of the heat exchanger, such as $\mathrm{H}_{2}$ mass fraction, $\mathrm{HCl}$ mass fraction, $\mathrm{NH}_{3}$ mass fraction, water volume fraction, and oil volume fraction, are shown in Figure 10. As can be seen from Figure 9, the temperature of the multiphase fluid in tubes decreases gradually along the flow direction. When the fluid flows out of the tube outlet, the temperature drops from $176{ }^{\circ} \mathrm{C}$ to $146.9{ }^{\circ} \mathrm{C}$. The heat transfer process between tubes is far different from each other. Generally, the temperature outside the tube is lower, and the temperature in the center area is higher. The area with lower temperature is concentrated in the second pass, and the risk of ammonium chloride crystallization is higher in the second pass of the heat exchanger.

To explore the initial position of ammonium chloride, the distribution of ammonium chloride volume fraction in tubes at the highest outlet temperature $\left(154.37^{\circ} \mathrm{C}\right)$ and the lowest outlet temperature $\left(143.68{ }^{\circ} \mathrm{C}\right)$ is analyzed. Figure 11 shows the distribution of ammonium chloride volume fraction in the first and second passes, respectively. It can be seen that less ammonium chloride is generated in the first pass of the tubes, and the volume fraction of ammonium chloride in the tubes with the highest and lowest temperatures is larger at the U-bend; after the U-bend, ammonium chloride begins to deposit after $1.7 \mathrm{~m}$ in the second pass. The temperature difference between the highest and lowest tubes is nearly $10{ }^{\circ} \mathrm{C}$, but the amount of ammonium chloride deposited varies greatly. It can be seen that uneven heat transfer during the heat transfer process leads to a great temperature difference, which will have a significant impact on the deposition and corrosion of ammonium chloride.

The mass transfer rates of $\mathrm{NH}_{3}$ and $\mathrm{HCl}$ in tubes at the outlet with the highest and lowest temperatures are explored, as shown in Figure 12. The average mass transfer rates of $\mathrm{HCl}$ and $\mathrm{NH}_{3}$ are $3.30 \mathrm{e}-06 \mathrm{~kg} / \mathrm{m}^{3} \mathrm{~s}$ and $1.53 \mathrm{e}-06 \mathrm{~kg} / \mathrm{m}^{3} \mathrm{~s}$, respectively. Because the reaction of $\mathrm{NH}_{3}$ with $\mathrm{HCl}$ is equimolar, the consumption order of $\mathrm{NH}_{3}$ and $\mathrm{HCl}$ is the same. According to the actual production data, the plugging rate is estimated to be $7.364 \mathrm{e}-06 \mathrm{~kg} / \mathrm{m}^{3} \bullet$ s, so the UDF can accurately simulate the actual operation conditions to explore the crystallization mechanism of ammonium chloride.

Due to the cooling effect of the shell-side fluid in the tube side, the temperature near the inner wall of tubes is low. If there are $\mathrm{HCl}$ and $\mathrm{NH}_{3}$ gas compositions, it is possible to form ammonium chloride. In order to explore the variation in the ammonium chloride crystallization region in a single tube, a tube with a temperature of $166^{\circ} \mathrm{C}$ on the inlet of the tube side is selected for analysis. Figure 14 show the variation of isotherm at $166{ }^{\circ} \mathrm{C}$ along the flow direction in the selected tube. It can be seen that the $166^{\circ} \mathrm{C}$ isotherm gradually shrinks to the center of the tube along the flow direction. It means that the low-temperature area gradually increases, and the crystallizing area becomes larger. When the crystallization area extends to the center of the tube, the tube will be blocked.

The crystallization rates of the single tube on two planes are further analyzed, which are divided into horizontal $X$ direction and numerical $Y$ direction. Figure 15 shows the crystallization rate distributions in $X$ direction and $Y$ direction at different sections along the flow direction of the tube. As can be seen, the crystallization rate near the two ends of the wall in the $X$ direction is larger, whereas the crystallization rate in the center area is smaller. The same rule happens in the $Y$ direction. As the multiphase fluid flows downstream along the flow direction, the crystallization rate increases gradually in both $X$ and $Y$ directions. In each section, the crystallization rate near the wall is far greater mainly due to the lower temperature near the wall. 
TABLe 2: The grid accuracy test.

\begin{tabular}{lcccc}
\hline & Inlet temperature $/{ }^{\circ} \mathrm{C}$ & Calculate outlet temperature $/{ }^{\circ} \mathrm{C}$ & Actual outlet temperature $/{ }^{\circ} \mathrm{C}$ & Error $/ \%$ \\
\hline Tube side & 176 & 146.9 & 147.3 & 0.27 \\
Shell side & 122.5 & 154.6 & 153 & 1.03 \\
\hline
\end{tabular}

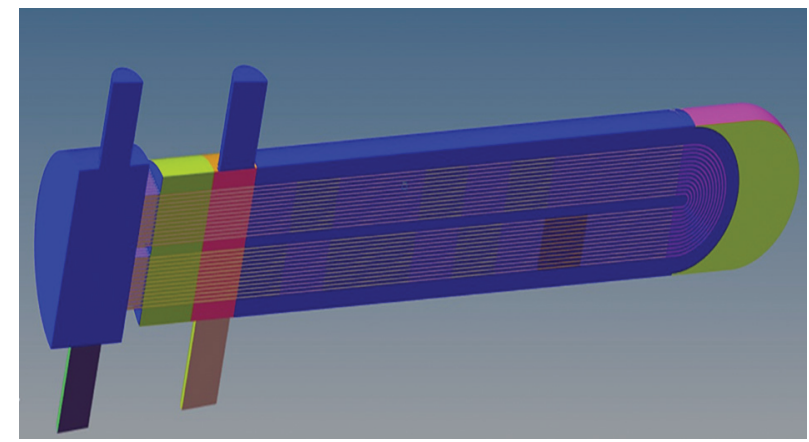

Figure 7: Geometric model of heat exchanger E1103 B.

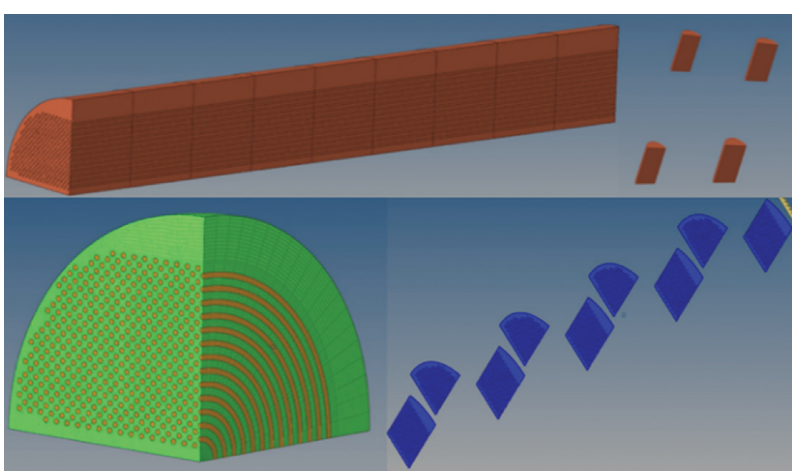

FIgURE 8: Mesh generation of heat exchanger E1103 B.

Table 3: Physical parameters of the tube-side medium.

\begin{tabular}{lcccc}
\hline & Density $/\left(\mathrm{kg} / \mathrm{m}^{3}\right)$ & Viscosity $/(\mathrm{Pa} \mathrm{s})$ & Thermal conductivity $/(\mathrm{W} / \mathrm{m} \mathrm{k})$ & Specific heat $/(\mathrm{J} / \mathrm{kg} \mathrm{K})$ \\
\hline Diesel & 873.7 & 0.006566 & 0.1237 & 2135 \\
Gas-phase mixture & Ideal gas model & $1.16 \mathrm{E}-05$ & 0.254 & 14569 \\
\hline
\end{tabular}

TABle 4: Physical parameters of the shell-side medium.

\begin{tabular}{lcccc}
\hline & Density $/\left(\mathrm{kg} / \mathrm{m}^{3}\right)$ & Viscosity $/(\mathrm{Pa} \mathrm{s})$ & Thermal conductivity $/(\mathrm{W} / \mathrm{m} \mathrm{k})$ & Specific heat $/(\mathrm{J} / \mathrm{kg} \mathrm{K})$ \\
\hline Diesel & 873.7 & 0.006566 & 0.1237 & 2135 \\
Hydrogen & Ideal gas model & $1.16 \mathrm{E}-05$ & 0.254 & 14569 \\
\hline
\end{tabular}

The distribution of $\mathrm{H}_{2}$ mass fraction, gas phase, velocity field, and velocity vector diagram at the U-shaped bend are shown in Figure 16. As can be seen from Figure 16(a), the hydrogen content at the bend is relatively high on the inside and outside, reaching $98.5 \%$, which provides the possibility for hydrogen-induced cracking. When the substance in tubes passes through the U-shaped bend, the distribution of the composition and velocity appears different due to centrifugal force and the gas-liquid phase position switches. The liquid phase rushes to the outside wall while flowing through the U-bend and continues to flow forward at the bottom of tubes in the second pass, as shown in Figure 16(b) and Figure 16(c) $[29,30]$. From the velocity vector diagram in Figure 16(d), it shows that the fluid flows through the curved tubes from the first pass, which imposes an impact on the outer wall of the curved tubes at a larger speed. Meanwhile, under the action of centrifugal force, the particles of ammonium chloride will also erode the outer wall surface, and the erosion angle is larger than the right angle, which is easier to cause corrosion $[31,32]$. The U-bend is at 


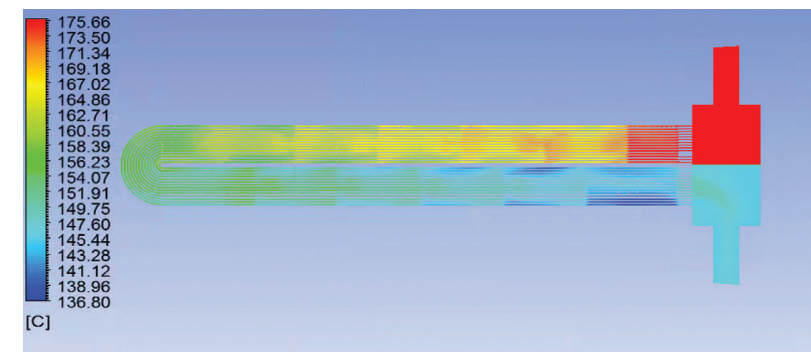

FIGURE 9: Temperature distribution along the tube side of the heat exchanger.

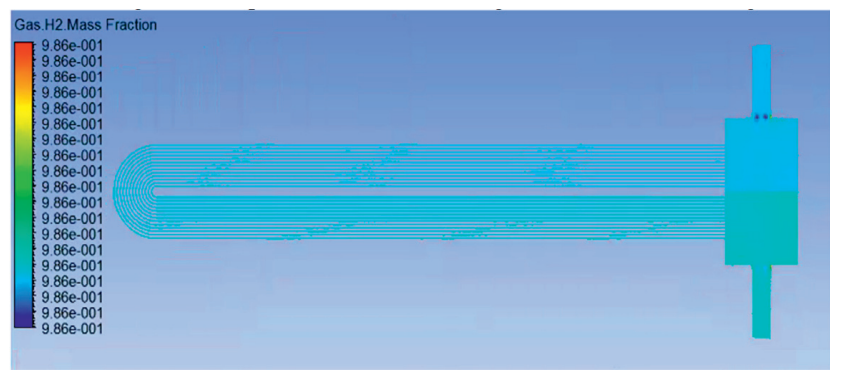

(a)

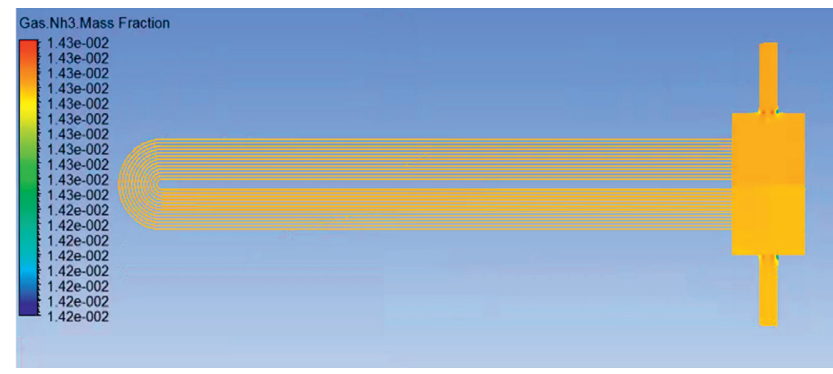

(c)

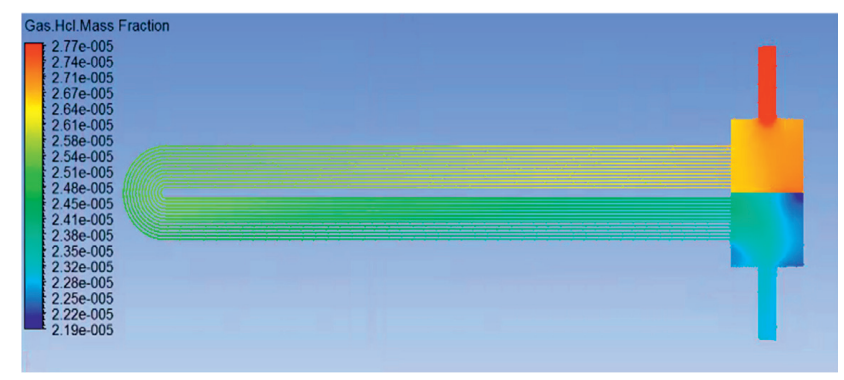

(b)

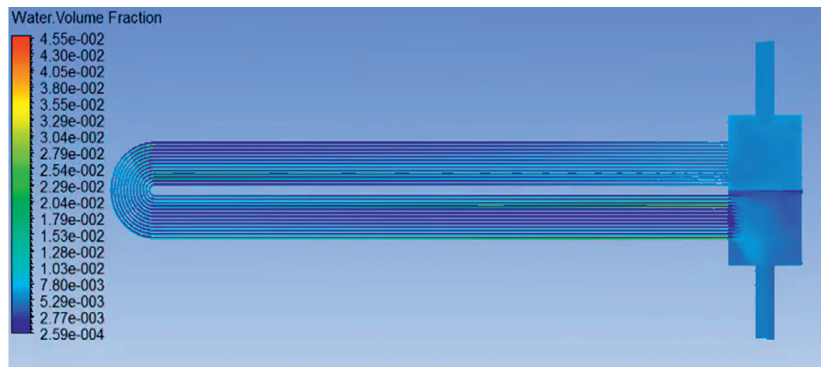

(d)

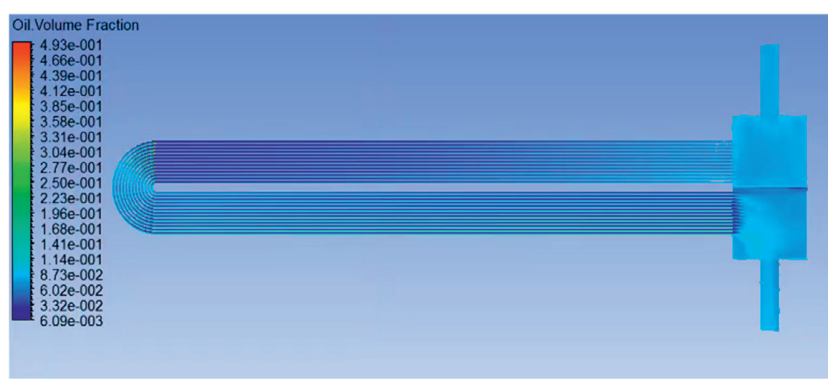

(e)

Figure 10: Distribution of various phases in the multiphase system of the tube side of the heat exchanger. (a) Contour of $\mathrm{H}_{2}$ mass fraction. (b) Contour of $\mathrm{HCl}$ mass fraction. (c) Contour of $\mathrm{NH}_{3}$ mass fraction. (d) Contour of water volume fraction. (e) Contour of oil volume fraction.

high-risk corrosion area because of the existence of a large amount of hydrogen, high impact force, high speed, and erosion of ammonium chloride particles.

\section{Improvement Measures}

In the actual production process, intermittent water injection was used to alleviate the corrosion of ammonium chloride, but there was still ammonium salt deposition in E1103 B. Therefore, it is necessary to explore the ways to reduce the deposition of ammonium chloride to slow down its corrosion. In this article, the mitigation of ammonium salt crystal corrosion is discussed in two ways: increasing the inlet temperature of tubes and increasing the amount of water injection. When the inlet temperature of tubes is increased, the composition distribution of the inlet fluid remains unchanged. And the crystallization equilibrium temperature under the operation condition is unchanged. With the process of heat transfer, the outlet temperature will increase obviously, and the amount of crystallization will 


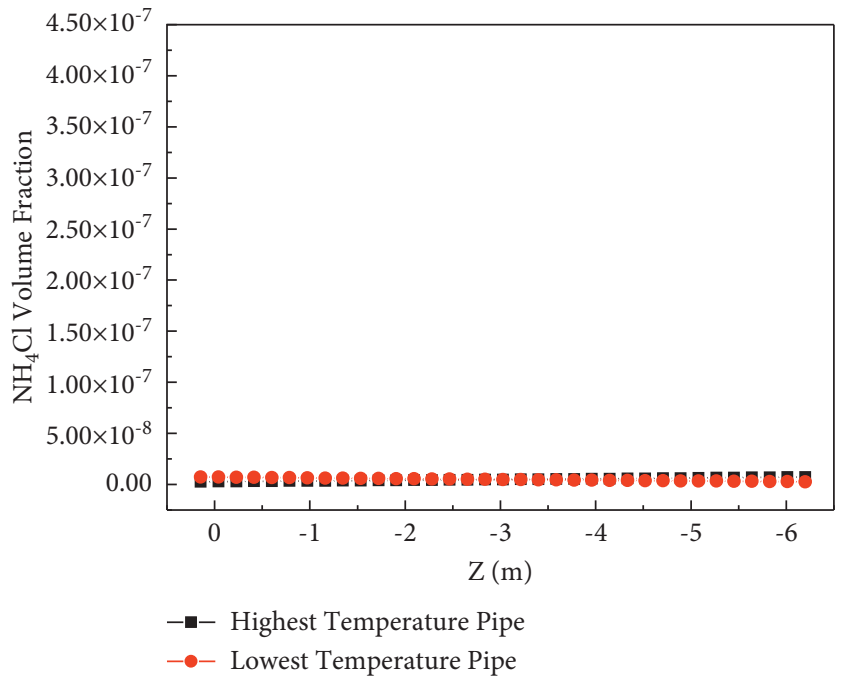

(a)

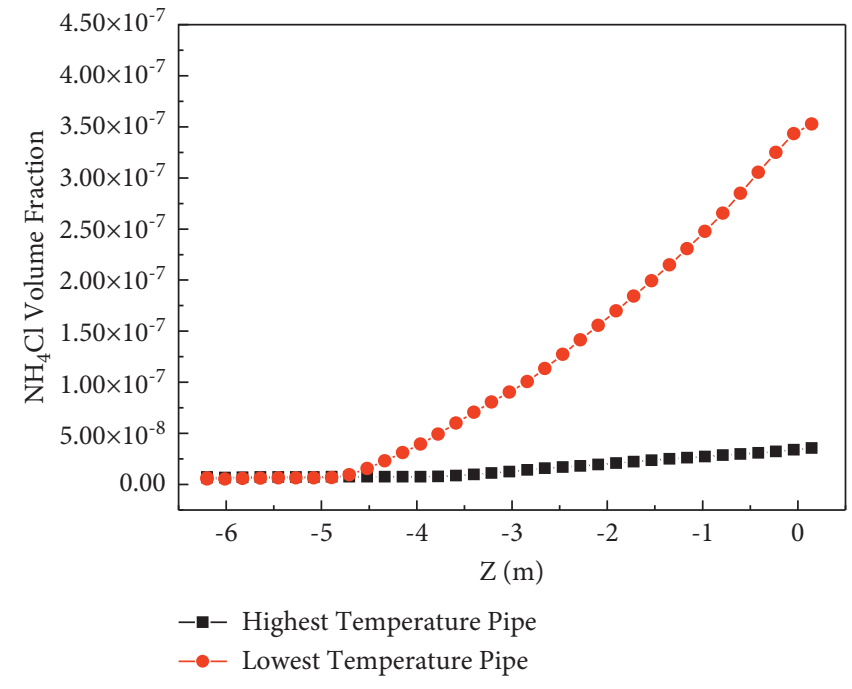

(b)

Figure 11: The overall distribution of the ammonium chloride volume fraction. (a) The volume fraction of ammonium chloride in the first pass with the highest and lowest temperatures tube at the outlet. (b) The volume fraction of ammonium chloride in the second pass with the highest and lowest temperatures tube at the outlet.

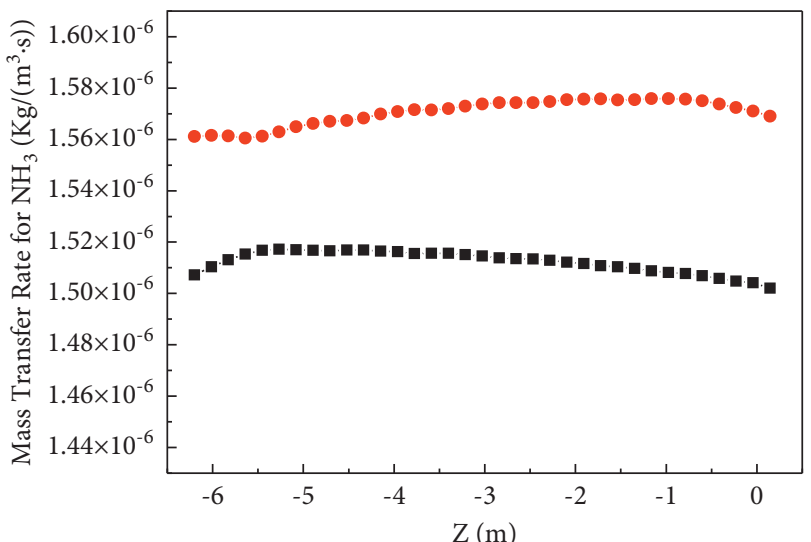

-- Highest Temperature Pipe

- - Lowest Temperature Pipe

Figure 12: Mass transfer rates of $\mathrm{NH}_{3}$ in tubes with the highest and lowest temperatures.

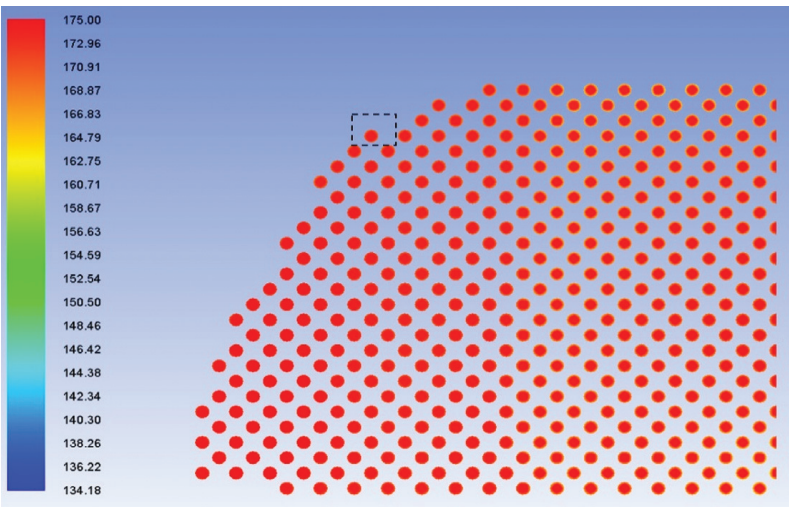

FIGURE 13: Schematic diagram of single tube selection. 


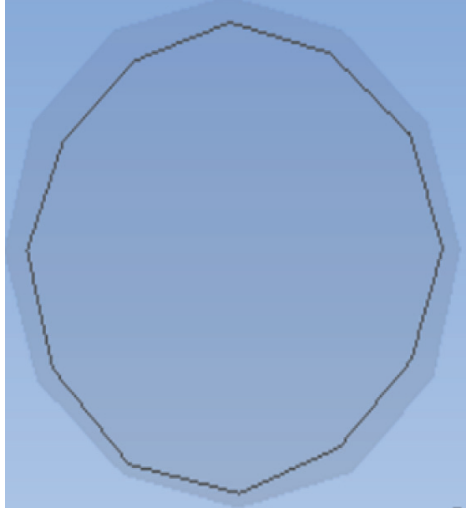

(a)

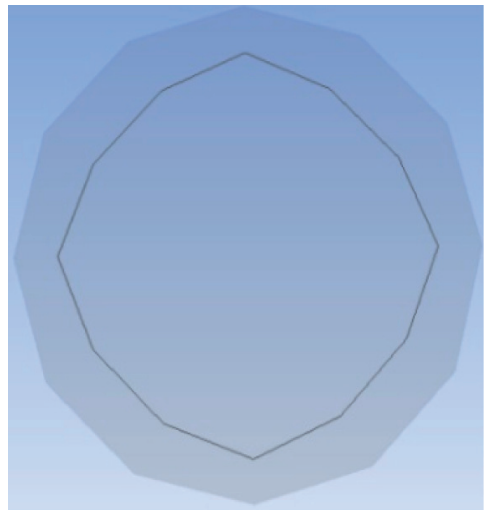

(b)

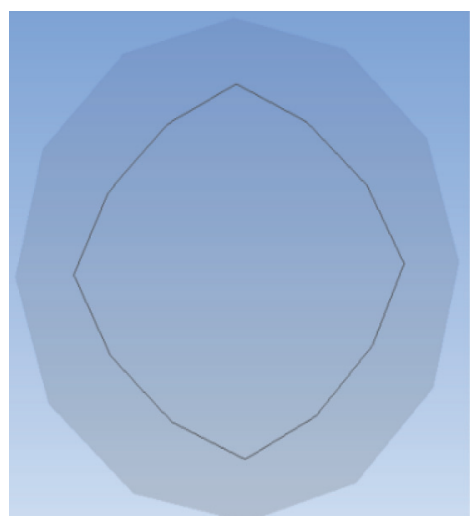

(c)

Figure 14: Variation of isotherm at $166{ }^{\circ} \mathrm{C}$ along the flow direction of a single tube: (a) $z=2.2 \mathrm{~m}$. (b) $z=2.6 \mathrm{~m}$. (c) $z=3.4 \mathrm{~m}$.

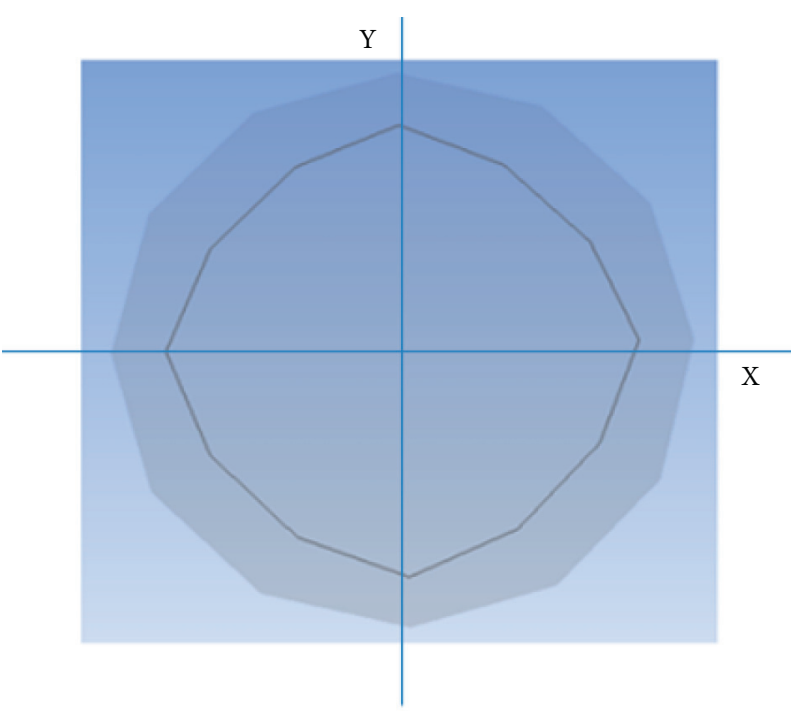

(a)

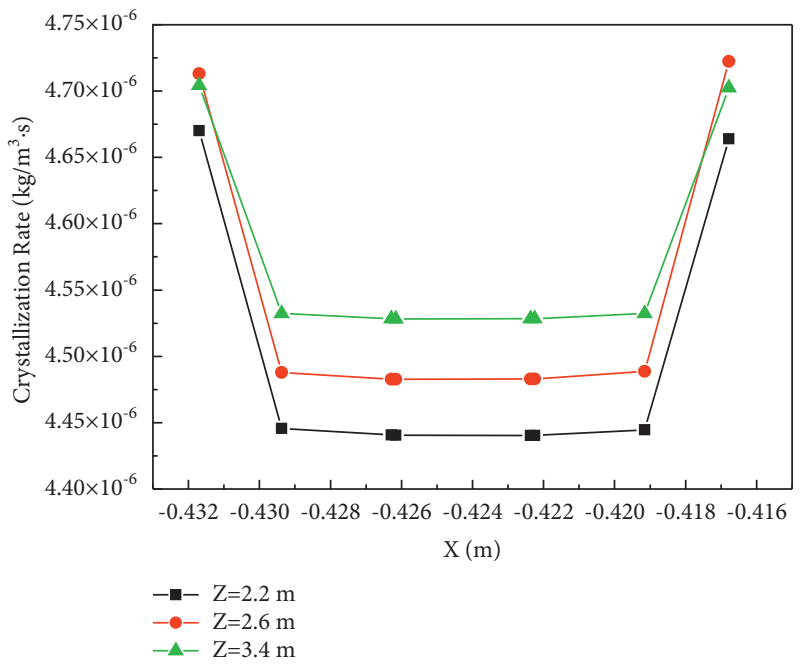

(b)

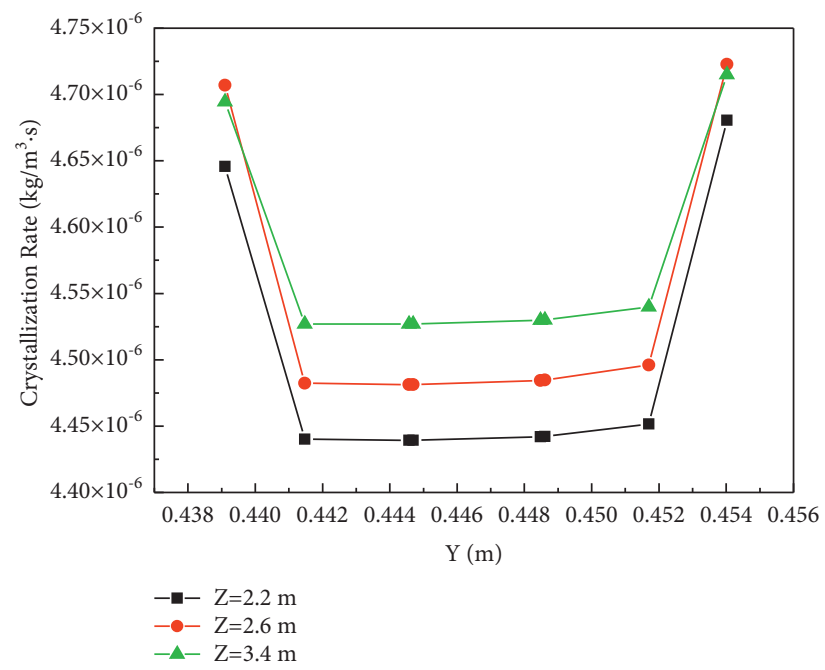

(c)

Figure 15: Distribution of crystallization rate on different cross sections. (a) X, Y coordinate schematic diagram. (b) Distribution of crystallization rate in $X$ direction on different cross sections. (c) Distribution of the crystallization rate in $Y$ direction on different cross sections. 


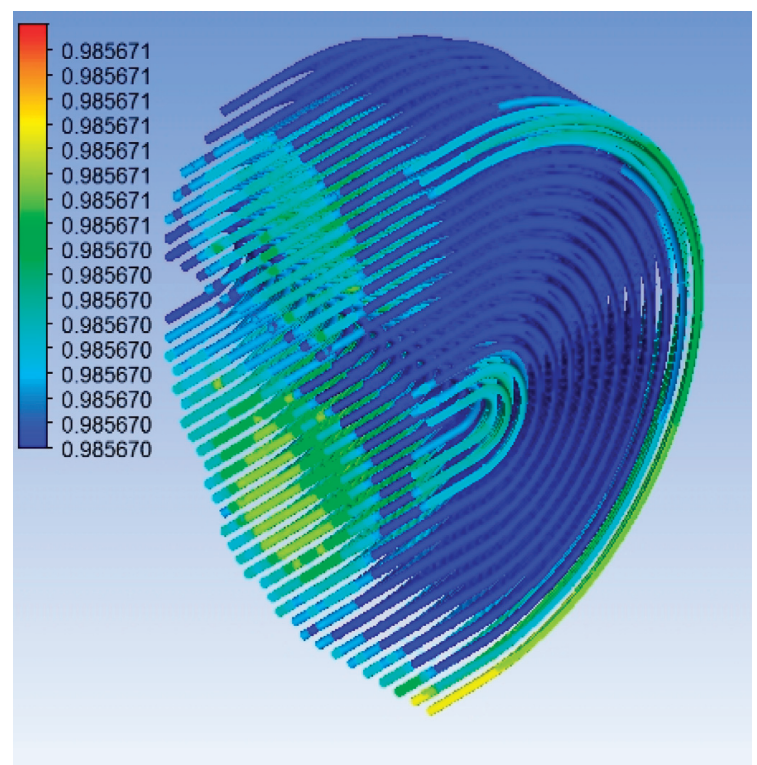

(a)

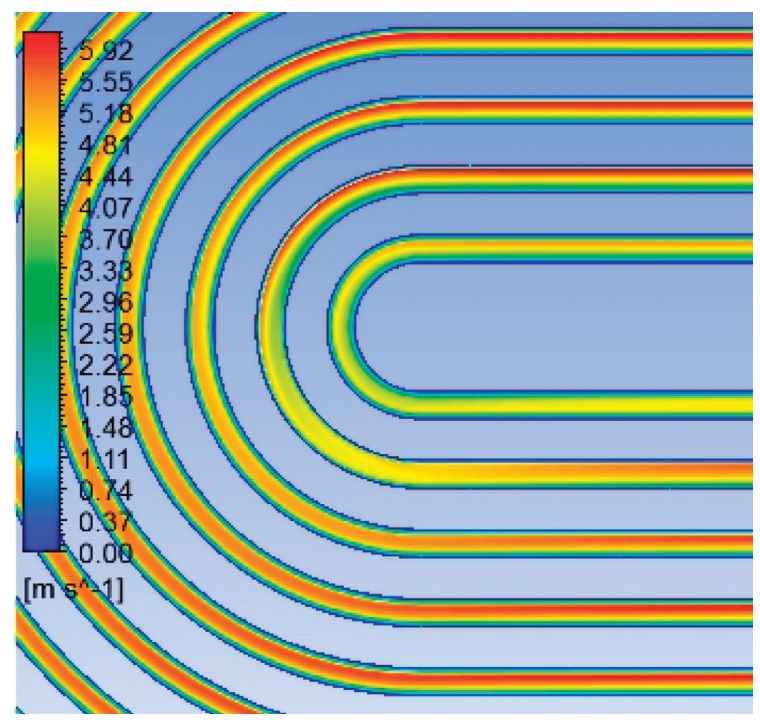

(c)

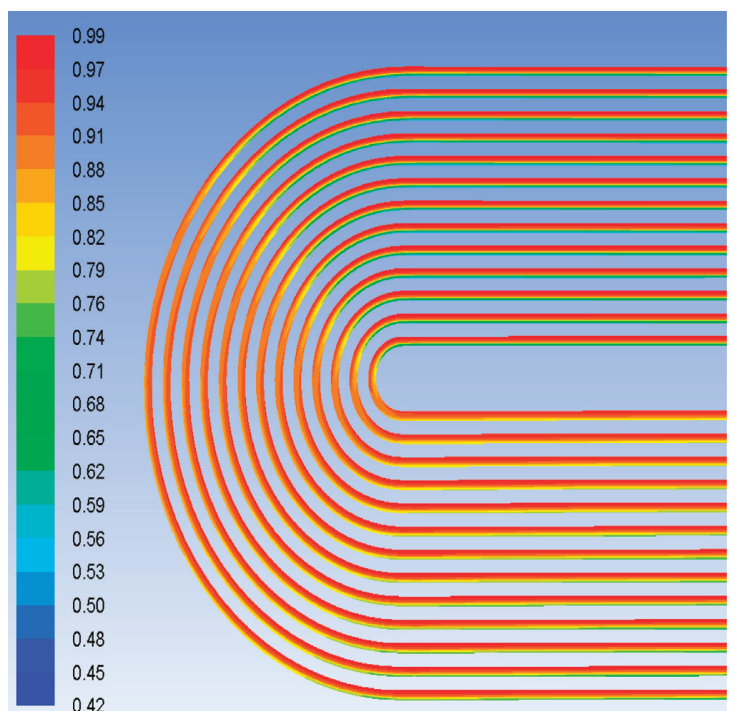

(b)

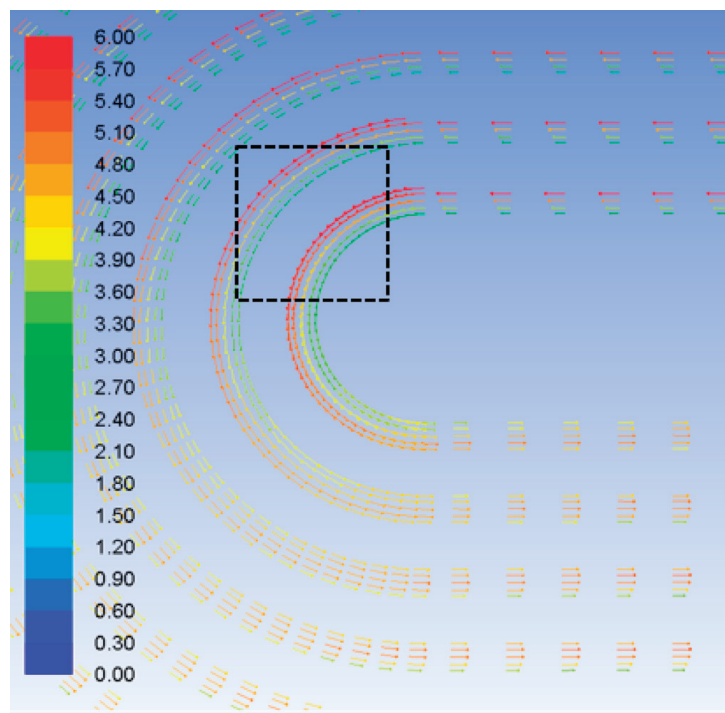

(d)

Figure 16: Contours of heat exchanger U-shaped bends. (a) $\mathrm{H}_{2}$ mass fraction distribution diagram. (b) Gas phase distribution diagram. (c) Velocity cloud diagram. (d) Velocity vector diagram.

decrease greatly. With the increase of water injection, the amount of ammonium chloride generated by the heat exchanger is constant, but there will be much ammonium chloride to dissolve and the distribution of ammonium chloride will be changed.

5.1. Increase in the Inlet Temperature. In this section, the inlet temperature of the tube side is increased so that the outlet temperature is above the crystallization temperature of ammonium chloride as far as possible. Thus, the temperatures of all tubes are higher than the crystallization temperature of ammonium chloride to reduce the amount of ammonium chloride. In order to obtain the most effective measures to mitigate the corrosion of ammonium chloride, the following cases are analyzed.
5.1.1. Increase in the Inlet Temperature to $195{ }^{\circ} \mathrm{C}$. According to the actual conditions, the temperature of the inlet temperature in tube side is raised to $195{ }^{\circ} \mathrm{C}$, the outlet temperature of the lowest tube at the outlet increases from $141.7^{\circ} \mathrm{C}$ to $149^{\circ} \mathrm{C}$, with a temperature increase of nearly $7^{\circ} \mathrm{C}$.

Under actual production conditions, the inlet temperature of the fluid is $176{ }^{\circ} \mathrm{C}$. According to the ammonium chloride crystal equilibrium curve, it is possible to generate ammonium chloride in the fluid. When the inlet temperature of tubes is raised, the time for the temperature to be lower than the crystallization temperature of ammonium chloride will be delayed, that is, the position where ammonium chloride begins to form will move downstream. When the inlet temperature of tubes is raised to $195^{\circ} \mathrm{C}$, the crystallization point is moved downstream by $2.89 \mathrm{~m}$, and 


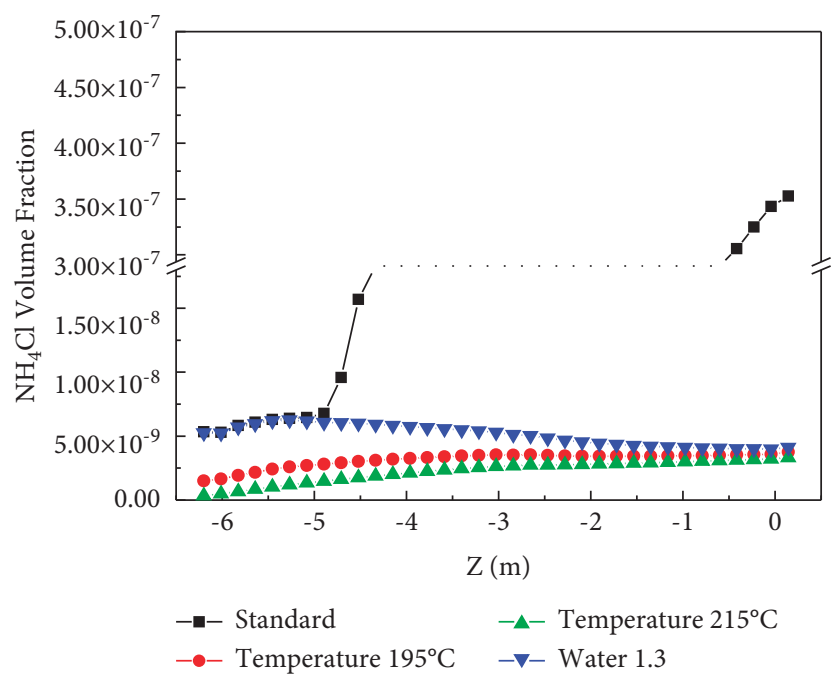

FIgURE 17: Comparison diagram of the volume fraction of ammonium chloride in the tube at the lowest temperature under three working conditions.

the crystallization amount of ammonium chloride salt is reduced. The amount of ammonium chloride produced in the second pass of the lowest temperature tube at the outlet is shown in Figure 17.

In order to carefully investigate whether the ammonium chloride generated can be dissolved by the injected water with the improvement measures, the amount of ammonium chloride that can be dissolved is deduced according to the solubility of ammonium chloride in water and then compared with the real amount of ammonium chloride generated, to see whether the improvement measures are effective. As shown in Figure 18, when increased by $19{ }^{\circ} \mathrm{C}$, the amount of ammonium chloride generated in the first pass is less than that which can be dissolved. The amount of ammonium chloride generated in the first pass can be dissolved by water. The amount of ammonium chloride generated in the second pass is greater than the amount dissolved; that is, the amount of ammonium chloride generated in the second pass cannot be completely dissolved.

5.1.2. Increase in the Inlet Temperature to $215^{\circ} \mathrm{C}$. When the inlet temperature of tubes is raised to $215^{\circ} \mathrm{C}$, and the outlet temperature of the lowest temperature tube is raised from $141.7{ }^{\circ} \mathrm{C}$ to $155.4{ }^{\circ} \mathrm{C}$, with a temperature increase of nearly $15{ }^{\circ} \mathrm{C}$. When the inlet temperature of tubes is increased to $215^{\circ} \mathrm{C}$, the crystallization point is delayed by $4.46 \mathrm{~m}$. The crystallization amount of ammonium chloride is greatly reduced. The amount of ammonium chloride produced is shown in Figure 17.

Figure 19 shows the comparison of the amount of ammonium chloride generated and dissolved when the inlet temperature of tubes is increased to $39{ }^{\circ} \mathrm{C}$. It can be seen from Figure 19 that the amount of ammonium chloride generated in the first pass or the second pass is lower than the amount of ammonium chloride that can be dissolved. In other words, the amount of ammonium chloride formed can be completely dissolved by water. The increase in the inlet temperature of tubes to $215{ }^{\circ} \mathrm{C}$ can effectively reduce the deposition of ammonium chloride and alleviate the corrosion of ammonium chloride.

5.2. Increase in the Amount of Water Injection. By raising the amount of water injected, the appropriate amount of water injection dissolves the ammonium chloride salts generated in tubes and takes it away from the heat exchanger with the fluid. Increase the injection water by $30 \%$ under standard operating conditions, and the ammonium chloride production rate of the lowest temperature tube is reduced from $3.53 \mathrm{e}-07$ to $4.11 \mathrm{e}-09$.

As the increase of water injection does not change the inlet temperature, the position of crystallization point does not change. The ammonium chloride accumulation along the flow direction of the tube with the lowest temperature under water injection and without water injection is considered. As shown in Figure 20, the accumulation of ammonium chloride after water injection is significantly lower than that without water injection. A considerable amount of ammonium chloride is dissolved in the water after water injection. Without water injection, the cumulative amount at the outlet is $6.0 \mathrm{e}-09 \mathrm{~kg} / \mathrm{s}$. While after water injection, the cumulative amount is $9.3 \mathrm{e}-10 \mathrm{~kg} / \mathrm{s}$, which is reduced by $85 \%$. The effect of water injection is obvious.

After increasing the injection amount by $30 \%$, the amount of ammonium chloride generated and dissolved along the flow direction of the tube at the lowest temperature is shown in Figure 21. As can be seen from Figure 21, the amount of ammonium chloride produced in the first and second passes is lower than the amount dissolved. When the water injection is increased by $30 \%$, the ammonium chloride will be dissolved completely.

The volume fraction of ammonium chloride generated by the lowest temperature tube after the improved measures is compared with that under standard conditions: when increasing the inlet temperature to $195^{\circ} \mathrm{C}$, the amount of 


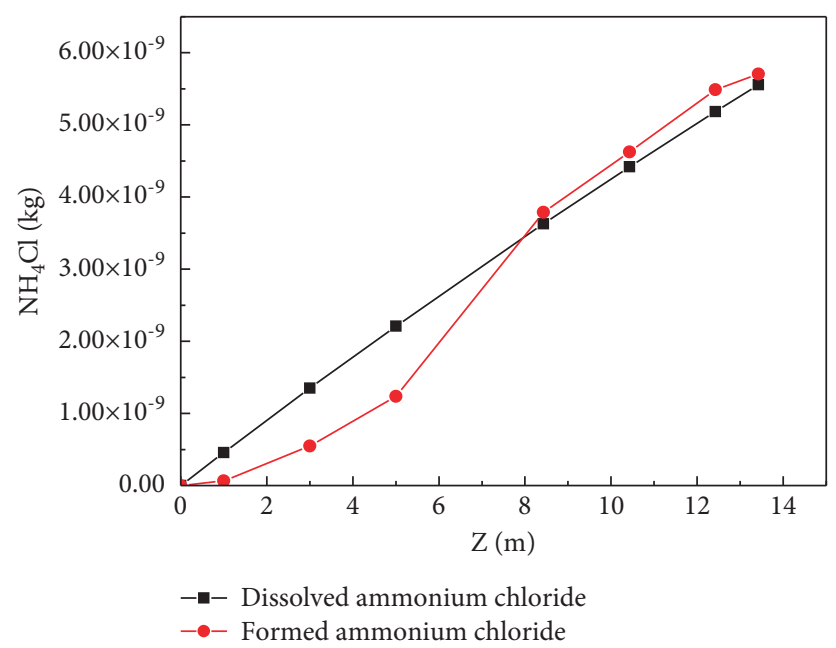

FIGURE 18: Dissolved and generated ammonium chloride at an inlet temperature of $195^{\circ} \mathrm{C}$.

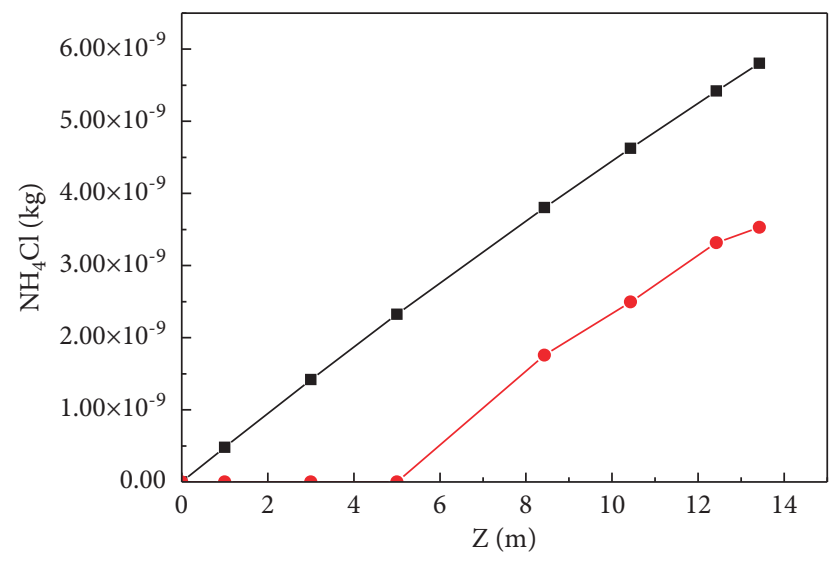

-m- Dissolved ammonium chloride

- - Formed ammonium chloride

FIgURE 19: Dissolved and formed ammonium chloride at an inlet temperature of $215{ }^{\circ} \mathrm{C}$.

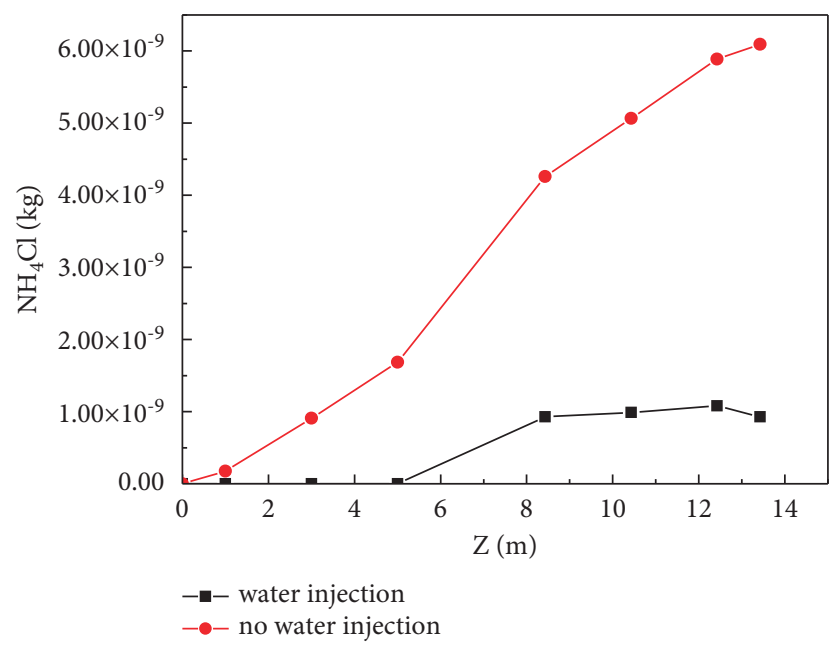

Figure 20: Comparison of ammonium chloride accumulation with water injection and without water injection. 


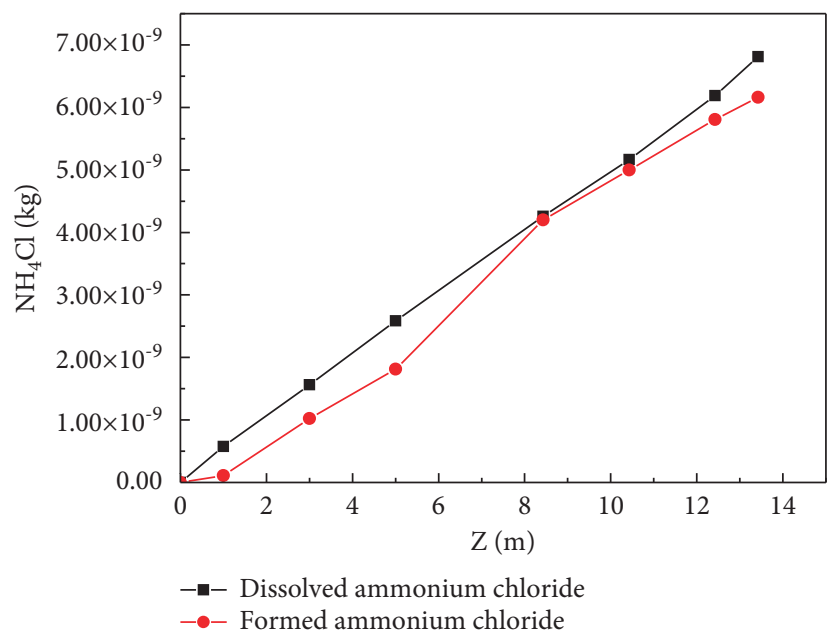

FIGURE 21: Comparison of ammonium chloride produced and dissolved by $30 \%$ increase of water injection.

ammonium chloride decreased to $1.06 \%$; when heating up to $215^{\circ} \mathrm{C}$, its ammonium chloride volume fraction is reduced to $0.94 \%$; and when the injection water increased by $30 \%$, ammonium chloride volume fraction reduces to $1.16 \%$. By comparison, the best effect is to increase the inlet temperature to $215{ }^{\circ} \mathrm{C}$, which greatly reduces the production of ammonium chloride and ensures the continuous and safe operation of the heat exchanger.

\section{Conclusions}

(1 ) Aiming at the problem of ammonium salt crystallization of the high-pressure heat exchanger in hydrogenation unit, the potential corrosion risk position under the practical flow condition is studied. Through computational fluid dynamics simulation analysis, the causes of multifactor corrosion are determined and propose the methods of corrosion risk analysis, prediction, prevention, and control.

(2) The internal temperature field and concentration distribution in the high-pressure heat exchanger are simulated numerically, and the crystal corrosion of ammonium chloride is calculated by using UDF. The ammonium chloride corrosion of heat exchanger tubes is predicted by using the key parameters such as ammonium chloride crystallization temperature, ammonium chloride volume fraction, and mass transfer rate of $\mathrm{NH}_{3}$ and $\mathrm{HCl}$. The risk of ammonium chloride deposition is higher after $1.7 \mathrm{~m}$ of the second pass.

(3) The crystallization behavior of ammonium chloride in a single tube is explored: along the flow direction, the crystallization area gradually expands from the inner wall of the tube to the center, and the inner wall of the tube has a higher crystallization rate than other locations due to low temperature.

(4) For the U-bend corrosion cracking, the results of field inspection and sampling analysis show that the corrosion cracking was hydrogen-induced cracking. Through the analysis of the flow structure of the multiphase body and the distribution of gas and liquid in the heat exchanger, the reasons for the cracking are as follows: the excessive hydrogen content in the bend, high impact force, excessive flow velocity, and erosion risk of ammonium chloride particles.

(5) In order to reduce the phenomenon of ammonium salt crystallization after water injection under actual production conditions, the improvement measures of raising the temperature to $195{ }^{\circ} \mathrm{C}$ and $215{ }^{\circ} \mathrm{C}$ and increasing the water injection volume by $30 \%$ are put forward. By comparison, the effect of increasing the inlet temperature of the tube to $215{ }^{\circ} \mathrm{C}$ is more obvious, and the amount of crystallization is reduced the most.

\section{Data Availability}

The data used to support the findings of this study are available from the corresponding author upon request.

\section{Conflicts of Interest}

The authors declare that there are no conflicts of interest regarding the publication of this article.

\section{Acknowledgments}

The authors acknowledge the financial support of the National Key Technology R\&D Program of China (2015BAK39B02) and National Key Science and Technology R\&D Plan (2021YFB3300133).

\section{References}

[1] M. H. Sliem, E. M. Fayyad, A. M. Abdullah et al., "Monitoring of under deposit corrosion for the oil and gas industry: a review," Journal of Petroleum Science and Engineering, vol. 204, 2021. 
[2] U. Klein, A. Zunkel, and A. Eberle, "Breakdown of heat exchangers due to erosion corrosion and fretting caused by inappropriate operating conditions," Engineering Failure Analysis, vol. 43, pp. 271-280, 2014.

[3] M. Ali, A. Ul-Hamid, L. M. Alhems, and A. Saeed, "Review of common failures in heat exchangers - Part I: mechanical and elevated temperature failures," Engineering Failure Analysis, vol. 109, 2020.

[4] K. V. Akpanyung, R. T. Loto, and M. A. Fajobi, "An overview of ammonium chloride (NH4Cl) corrosion in the refining unit," Journal of Physics: Conference Series, vol. 1378, 2019.

[5] F. Darihaki, J. Zhang, R. E. Vieira, and S. A. Shirazi, "The nearwall treatment for solid particle erosion calculations with CFD under gas and liquid flow conditions in elbows," Advanced Powder Technology, vol. 32, no. 5, pp. 1663-1676, 2021.

[6] A. Groysman, "Corrosion problems and solutions in oil, gas, refining and petrochemical industry," Koroze a ochrana materialu, vol. 61, no. 3, pp. 100-117, 2017.

[7] L. K. R. Horvath, "Implementation of best practices for water washes in hydroprocessing units," in Proceedings of the 2003 NACE International Publications Division, Houston, USA, December 2003.

[8] J. Turner, "Design of hydroprocessing effluent water wash systems," in Proceedings of the 1998 NACE International Publications Division, Houston USA, March 1998.

[9] Y. Liu, Y. Zhao, and J. Yao, "Synergistic erosion-corrosion behavior of $\mathrm{x} 80$ pipeline steel at various impingement angles in two-phase flow impingement," Wear, vol. 466-467, Article ID 203572, 2021.

[10] C. A. Silva, L. B. Varela, F. O. Kolawole, A. P. Tschiptschin, and Z. Panossian, "Multiphase-flow-induced corrosion and cavitation-erosion damages of API 5L X80 and API 5DP grade S steels," Wear, vol. 452-453, 2020.

[11] J. Owen, E. Ducker, M. Huggan, C. Ramsey, A. Neville, and R. Barker, "Design of an elbow for integrated gravimetric, electrochemical and acoustic emission measurements in erosion-corrosion pipe flow environments," Wear, vol. 428429, pp. 76-84, 2019.

[12] Q. Chen and W. Zhu, "Investigation on coupling of multiphysics in flow reaction between $\mathrm{NH} 3(\mathrm{~g})$ and $\mathrm{HCl}(\mathrm{g})$ in atmospheric tower overhead," Corrosion and Protection In Petrochemical Industry, vol. 37, no. 03, pp. 6-12, 2020.

[13] A. Sun and D. Fan, NACE International Store - 10359 Prediction, Monitoring, and Control of Ammonium Chloride Corrosion in Refining Processes, 2010.

[14] M. Awais and A. A. Bhuiyan, "Recent advancements in impedance of fouling resistance and particulate depositions in heat exchangers," International Journal of Heat and Mass Transfer, vol. 141, pp. 580-603, 2019.

[15] H. Jin, X. Chen, G. Ou, and J. Zhang, "Potential failure analysis and prediction of multiphase flow corrosion thinning behavior in the reaction effluent air cooler system," Engineering Failure Analysis, vol. 109, 2020.

[16] B. R. Munson and M. S. Cayard, "Thermodynamic derivations of various ammonium salt deposition equations common to the refining industry," Corrosion, vol. 74, no. 10, pp. 1158-1163, 2018.

[17] B. Kuz 'nicka, "Erosion-corrosion of heat exchanger tubes," Engineering Failure Analysis, vol. 16, no. 7, pp. 2382-2387, 2009.

[18] American Petroleum Institute, "Damage Mechanisms Affecting Fixed Equipment in the Refining Industry," in API recommended practice 571, 2nd edn, American Petroleum Institute API
Publishing Services, 1220 L Street, NW, Washington, DC, USA, April 2011.

[19] X. C. W. W. Gerberich, "The kinetics and micromechanics of HydrogenAssisted cracking in Fe-3 pct Si single crystals," Metallurgical transactions A, API RP 571-2011, vol. 22, no. 1, pp. 59-70, Washington, 1991.

[20] S. Jani, M. Marek, R. F. Hochman, and E. I. Meletis, "A mechanistic study of transgranular stress corrosion cracking of type 304 stainless steel," Metallurgical transactions A, vol. 22, no. 6, pp. 1453-1461, 1991.

[21] S. Mahajanam, F. Addington, A. Barba et al., "Ammonium chloride corrosion in the refining industry," Corrosion, vol. 2017, 2017.

[22] K. L. Edwards, ASM Handbook, Volume 11: Failure Analysis and Prevention, B. T. Becker and R. J. Shipley, Eds., pp. 747-897, ASM International, Geauga County, Ohio, 2004.

[23] American Petroleum Institute, Design, materials, fabrication, operation, and inspection guidelines for corrosion control in hydroprocessing reactor effluent air cooler (REAC) systems, in: API RP 932-B-2012, Washington, USA, SECOND EDITION, 2012.

[24] L. Zhao, Y. Yan, and X. Yan, "A semi-empirical model for $\mathrm{CO}_{2}$ erosion-corrosion of carbon steel pipelines in wet gas-solid flow," Journal of Petroleum Science and Engineering, vol. 196, 2021.

[25] O. A. Akbari, M. R. Safaei, M. Goodarzi et al., "A modified two-phase mixture model of nanofluid flow and heat transfer in a 3-D curved microtube," Advanced Powder Technology, vol. 27, no. 5, pp. 2175-2185, 2016.

[26] F. R. Menter, "Two-equation eddy-viscosity turbulence models for engineering applications," AIAA Journal, vol. 32, no. 8, pp. 1598-1605, 1994.

[27] F. Ghezali, A. Azzi, and A. Bouzidane, "Coupling of internal and external cooling of gas turbine blades," Mechanics \& Industry, vol. 15, no. 2, pp. 123-132, 2014.

[28] J. Zhang, A. Jiang, Y. Xin, and J. He, "Numerical investigation on multiphase erosion-corrosion problem of steel of apparatus at a well outlet in natural gas production," Journal of Fluids Engineering, vol. 140, no. 12, 2018.

[29] B. Bozzini, M. E. Ricotti, M. Boniardi, and C. Mele, "Evaluation of erosion-corrosion in multiphase flow via CFD and experimental analysis," Wear, vol. 255, no. 1-6, pp. 237-245, 2003.

[30] S. S. Brian C, M. Y. Kwei, and Y. Mark, Corrosion in Crude Distillation Unit Overhead Operations: A Comprehensive Review, NACE International Publications Division, Houston, TX, USA, Article ID 11360, 2011.

[31] S. M. El-Behery, M. H. Hamed, K. A. Ibrahim, and M. A. ElKadi, "CFD evaluation of solid particles erosion in curved ducts," Journal of Fluids Engineering, vol. 132, no. 7, 2010.

[32] F. Mohammadi and J. Luo, "Effects of particle angular velocity and friction force on erosion enhanced corrosion of 304 stainless steel," Corrosion Science, vol. 52, no. 9, pp. 2994-3001, 2010. 